\title{
Interest of Rehabilitation in Idiopathic Peripheral Facial Palsy in Children: A Case Report
}

\author{
Davelle Doungou Ngandzali ${ }^{1 *}$, Hasna Ouazzani ${ }^{1}$, Asma El Hanafi ${ }^{1}$, Karima Chgora ${ }^{1}$, Youness Abdelfettah ${ }^{1}$
}

\author{
${ }^{1}$ Department of Physical and Rehabilitation Medicine, University Hospital Mohammed VI Marrakesh Faculty of Medicine, Cadi \\ Ayyad University Marrakesh, Morocco
}

DOI: $10.36347 /$ sjmcr.2021.v09i04.026

| Received: 14.03.2021 | Accepted: 20.04.2021 | Published: 26.04.2021

*Corresponding author: Dr. Davelle Doungou Ngandzali

Abstract

Case Report

\begin{abstract}
Idiopathic peripheral facial palsy in children is a rare entity that often has a good prognosis. The use of rehabilitation treatment is one of the therapeutic means proposed. We report the case of an 8-year-old girl who presented with idiopathic peripheral facial palsy classified as Grade IV according to House Brackmamn. His management included medical treatment as well as rehabilitation coupled with personalized self-rehabilitation. The evolution was marked by the significant improvement at the end of the sessions to the Grade I-classified. Rehabilitation has great benefits aesthetic as well as in motor recovery.

Keywords: Idiopathic peripheral facial palsy, child, rehabilitation

ABBREVIATIONS: PFP, Peripheral Facial Palsy; ATCD, Antecedent; MPR, Physical Medicine and

Rehabilitation.

Copyright $(92021$ The Author(s): This is an open-access article distributed under the terms of the Creative Commons Attribution 4.0 International License (CC BY-NC 4.0) which permits unrestricted use, distribution, and reproduction in any medium for non-commercial use provided the original author and source are credited.
\end{abstract}

\section{INTRODUCTION}

Idiopathic peripheral facial palsy (PFP) also called Bell's palsy or Frigore's palsy is a rare entity in children unlike adults. It is little explored in children and its frequency ranges from 9 to $16 \%$ [1]. His clinic is generally dominated by disorders of facial motor skills, tearing and gout. Rehabilitative care is rarely offered because it is often ignored or deemed ineffective because poorly done. Although medical or surgical treatment is effective, functional rehabilitation provides a satisfactory response to the aesthetic concerns of patients. This observation illustrates a case of idiopathic peripheral facial paralysis in a child having prompted rehabilitation treatment.

\section{ObServation}

We report the case of an 8-year-old girl with no specific ATCD. She was referred to Physical Medicine and Rehabilitation (MPR) for the rehabilitative management of right idiopathic peripheral facial paralysis evolving for 3 days in an apyretic and non-traumatic context. The clinical examination had noted a lowering of the eyebrows, an erasure of the right frontal wrinkles, a right palpebral inocclusion, an erasure of the right nasolabial fold, a sagging of the right labial commissure, a deviation of the mouth to the right when smiling as well as difficulty in swelling the cheeks and whistling (Figures 1a, 2a, 3a). Paraclinically, the infectious assessment was normal, herpes serologies were negative and the lumbar puncture was not performed. Faced with these clinical and paraclinical elements, the hypothesis of idiopathic right peripheral facial paralysis classified as grade IV according to House Brackmamn was retained. She had received urgent care in otolaryngology including prednisone $1 \mathrm{mg} / \mathrm{kg} /$ day for seven days, artificial tears several times a day as well as the application of an occlusive eye pad at night. The rehabilitative care took place in 15 sessions at the rate of 3 sessions per week of 30 to 45 minutes coupled with a personalized home program. The session consist external and endo-oral massage, heating, relaxation, strengthening of the labial sphincter by games of breath and work of mimicry in a comparative way in front of the mirror for visual control.

At the end of the first session a selfrehabilitation sheet was given to the parent after a detailed explanation of the instructions below: Work the facial muscles by widening the eyes, frowning, lowering the lips, whistling and smiling; Superficial 
facial massage, symmetrical up and out of the face; Endo-oral massage; Slow stretch of the right cheek towards the middle of the face then lowering it down the face.
The evolution was marked by a significant recovery of the deficit: gain in the closing of the eyes, in swelling of the cheeks as well as in smile which made it possible to grade I according to House Brackmamn at the end of therapy (Figures 1b, 2b, 3b).

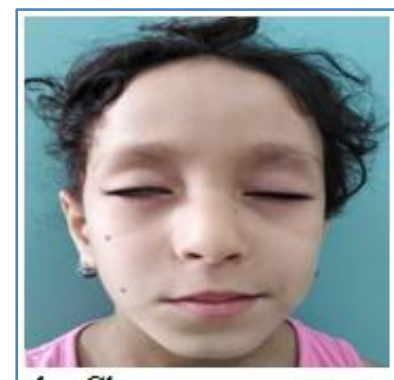

1a: Close eyes

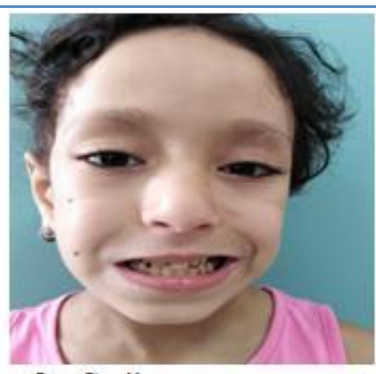

2a: Smile

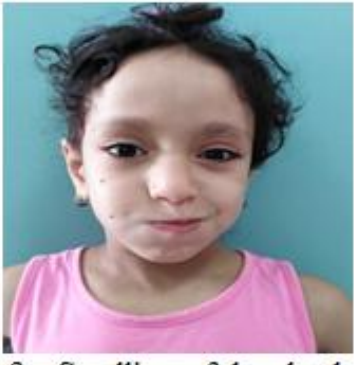

3a: Swelling of the cheeks

Fig-1a, 2a, 3a at the start of rehabilitation

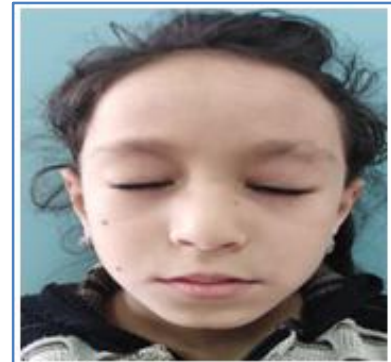

$1 \mathrm{~b}$ : Close eyes

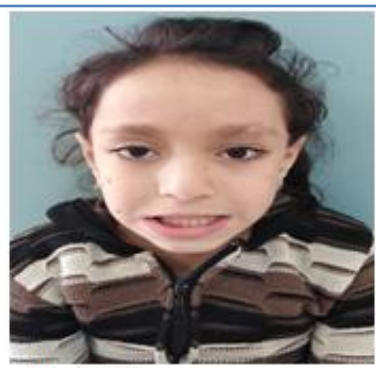

2b: Smile

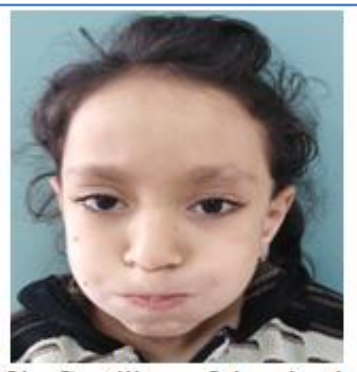

$3 \mathrm{~b}$ : Swelling of the cheeks

Fig-1b, 2b, 3b at the end of rehabilitation

\section{DISCUSSION}

The value of rehabilitation during idiopathic PFP in children has been the subject of very little study because fewer severe forms are described there compared to adults [2]. Idiopathic PFP in children often has a good prognosis; this prognosis depends on the severity of the neuronal injury, the delay in management and the patient's motivation [3]. Early treatment therefore allows rapid recovery. Untreated or treated late, PFP can cause significant aesthetic and functional discomfort that can have psychosocial repercussions, especially in children [2, 4]. A Cochrane review has successfully codified the management of peripheral facial palsy (PFP) in adults [5-7], but in children the studies remain inconsistent $[8,9]$.Yet those who proved benefits of rehabilitation were of low potency [10].

Most authors agree on starting whatever the etiology of PFP, a treatment that contains corticosteroid therapy with prednisolone, eye care as well as rehabilitation which remains the only treatment that can resolve the problem of psychic motor rehabilitation and aesthetic. Studies examining the consequences of disfigurement following PFP, regardless of its origin, agree on the seriousness of the psychosocial repercussions and on the quality of life of patients [11].The early speech therapy and the regular frequency of sessions positively contribute to the well-being of the child and his family [2, 12].

Early intervention was a key part of the prognosis for recovery, in our case. The established rehabilitation protocol focused on biofeedback work, coupled with self-rehabilitation has allowed almost complete recovery which may justify the passage from grade VI to grade I according to House Brackmamn at the end of sessions. We did not use electrical stimulation techniques which have been found to be inefficient in rehabilitating the mobility of facial musculature, and which may even be damaging and cause synkinesias and / or hemiface spasm.

The limits of rehabilitative treatment, in children, are therapeutic adherence as well as their response during the sessions, therefore the importance of regular motivation and confidence building according to age.

\section{CONCLUSION}

The management of idiopathic peripheral facial paralysis in adults as well as in children remains multidisciplinary. Rehabilitation is a valuable and indispensable aid for motor, psychological and aesthetic therapy. The early and regularity of reeducation sessions guaranteed the efficiency. 


\section{Authors's contributions}

All authors provided in into the medical care and therapy of the patient, as well as the writing this article they approved

\section{REFERENCES}

1. Maire R. Paralysie faciale : mise à jour pour le praticien. Revue Médicale Suisse. 2011; 7: 19011907

2. Gatignol P, Allano M, Robert M, Lannadère E, Tankéré F, Lamas G. Paralysie faciale périphérique chez l'enfant ou adolescent. Annales françaises d'oto-rhino-laryngologie et de pathologie cervicofaciale. 2013; 131: 75-103

3. Lafosse D. Prise en charge en kinésithérapie de la paralysie faciale périphérique non opérée. La Lettre d'ORL et de chirurgie cervico-faciale juillet-aoûtseptembre. 2009; 318

4. Bombo J, Manou B, Alloh A.D, Toowlys A, Kouakou J, Datié A, Nandjui B. Place de la rééducation dans le traitement des paralysies faciales périphériques: expérience du service de médecine physique et de réadaptation du CHU de Yopougon, Abidjan. Journal de réadaptation médicale. 2008;28:3-6

5. Salinas RA, Alvarez G, Daly F. Corticosteroids for Bell's palsy (idiopathic facial paralysis). Cochrane Database Syst Rev. 2010;(3):CD001942.
6. Gronseth GS, Paduga R. Evidence-based guideline update: steroids and antivirals for Bell palsy: report of the Guideline Development subcommittee of the American Academy of Neurology. Neurology. 2012; 79:2209-13.

7. Baugh RF, Basura GJ, Ishii LE. Clinical Practice Guideline: Bell's Palsy executive summary. Otolaryngol Head Neck Surg. 2013; 149:656-63.

8. Youshani AS, Mehta B, Davies K. Management of Bell's palsy in children: an audit of current practice, review of the literature and a proposed management algorithm. Em Med J 2013. http://dx.doi.org/10.1136/emermed-2013-202385.

9. Pitaro J, Waissbluth S, Daniel SJ. Do children with Bell's palsy benefit from steroid treatment? A systematic review. Int J Pediatr Otorhinolaryngol. 2012; 76:921-6.

10. Teixeira LJ, Valbuza JS, Prado GF. Physical therapy for Bell's palsy (idiopathic facial paralysis). Cochrane Database Syst Rev. 2011; (12):CD006283 (1469-493X)

11. Morel V. Réalité d'une paralysie faciale: De l'évaluation clinique du praticien au ressenti subjectif du patient. Mémoire soutenu pour l'obtention du certificat de capacité d'orthophoniste sous la direction de Peggy Gatignol - Paris VI, 2008.

12. Karp E. Réeducation faciale en tant que traitement non invasif pour la paralysie chronique du nerf facial. Otol Neurotol.2019 fevrier;40(2):241-245 